\begin{tabular}{|} 
Ambiente \& Água - An Interdisciplinary Journal of Applied Science \\
ISSN 1980-993X - doi:10.4136/1980-993X \\
www.ambi-agua.net \\
E-mail: ambi.agua@gmail.com
\end{tabular}

\title{
Potencial toxicológico de metais presentes em solos de cemitérios de Santa Maria - RS
}

\author{
doi:10.4136/ambi-agua.1723 \\ Received: 11 Aug. 2015; Accepted: 21 Nov. 2015 \\ Bruno Casanova Vilaverde Gomes ${ }^{1}$; Gislaine Kummer ${ }^{1}$; \\ Márcia Maria da Silva Monteiro Pereira²; Hécio José Izário Filho³; \\ Rodrigo Fernando dos Santos Salazar'; \\ Noeli Júlia Schüssler de Vasconcellos ${ }^{1 *}$ \\ ${ }^{1}$ Centro Universitário Franciscano (UNIFRA), Santa Maria, RS, Brasil \\ ${ }^{2}$ Laboratório Stollberg do Brasil, Guaratinguetá, SP, Brasil \\ ${ }^{3}$ Escola de Engenharia de Lorena (EEL/USP), Lorena, SP, Brasil \\ *Autor correspondente: e-mail: noejuabio@yahoo.com.br, \\ bruno.engenheiro.ambi@gmail.com, gislainekummer19@yahoo.com, \\ marcia.pereira@imerys.com, helcio@dequi.eel.usp.br, \\ r.f.s.salazar@gmail.com
}

\section{RESUMO}

A implantação de cemitérios sem projetos geoambientais e hidrogeográficos em solos sem propriedades estruturais e químicas necessárias para receber este tipo de atividade resulta que elementos tóxicos e lixiviados do cemitério percolem ao nível freático. Esta percolação leva a contaminação das águas subterrâneas, afetando drasticamente os recursos naturais e a saúde pública. Desta forma, a toxicidade de solos oriundos de cemitérios de Santa Maria foi avaliada. Paralelamente, as concentrações de Al, $\mathrm{Ca}, \mathrm{Cd}, \mathrm{Cr}, \mathrm{Cu}, \mathrm{Fe}, \mathrm{Mg}, \mathrm{Ni}, \mathrm{Pb}$ e $\mathrm{Zn}$ foram determinadas e comparadas com os limites de tolerância estabelecidos na Resolução 420 de 2013 do Conselho Nacional do Meio Ambiente. Oligochaetas da espécie Eisenia andrei foram empregadas como organismos bioindicadores em bioensaios, no formato ensaio-limite (controle versus tratamento), completamente casualizado, com três repetições, composto por sete tratamentos e dois níveis. Ao final do período de exposição, foram avaliados os efeitos de toxicidade aguda em oligochaetas, sendo feita a concentração letal média $\left(\mathrm{CL}_{50}\right)$. Os resultados da toxicidade aguda e crônica nos dois cemitérios analisados evidenciaram toxicidade $\left(\mathrm{CL}_{50}\right.$ 239,88 $\mathrm{mg} \mathrm{kg-}{ }^{1}$ e $\left.52,48 \mathrm{mg} \mathrm{kg}_{-}{ }^{1}\right)$ respectivamente e interferência no processo reprodutivo das oligochaetas. Pela análise química se detectou concentrações de metais tóxicos superiores aos valores de prevenção estabelecidos legalmente.

Palavras-chave: bioindicadores, oligochatas, metais tóxicos, toxicidade.

\section{Toxicological potential of metals found in soil of cemeteries in Santa Maria - RS}

\section{ABSTRACT}

Contamination with toxic elements and cemetery leachate may result when proper geoenvironmental and hydro geographic studies are not conducted and cemeteries are dug in soils 
without appropriate structure and chemical properties. This contamination may percolate through the water table, leading to groundwater contamination, which can dramatically affect natural resources and public health. The toxicity of soil from Santa Maria was evaluated in this context. In addition, concentrations of $\mathrm{Al}, \mathrm{Ca}, \mathrm{Cd}, \mathrm{Cr}, \mathrm{Cu}, \mathrm{Fe}, \mathrm{Mg}, \mathrm{Ni}, \mathrm{Pb}$ and $\mathrm{Zn}$ were determined and compared with the tolerance limits established by the National Environmental Council Resolution No. 420 of 2013. Oligochaetas of the Eisenia andrei species were used as bio indicators in the format bioassays-limit test (control versus treatment), in a completely randomized design with three replications, consisting of seven treatments and two levels. At the end of the exposure period, we evaluated the effects of acute toxicity in oligochaetas, considering the median lethal concentration $\left(\mathrm{LC}_{50}\right)$. The results of acute and chronic toxicity studies in the two analyzed cemeteries (urban and rural) showed toxicity $\left(\mathrm{CL}_{50} 239,88 \mathrm{mg} \mathrm{k}^{-1}\right.$ e 52,48 $\mathrm{mg} \mathrm{kg}^{1}$ ) and interference in the reproductive process of oligochaetas. We detected concentrations of toxic metals that exceeded legally established values.

Keywords: biomarkers, oligochaetas, toxic metals, toxicity.

\section{INTRODUÇÃO}

A Conferência de Estocolmo sobre o Meio Ambiente, realizada na capital da Suécia, Estocolmo, no ano de 1972, estreitou relações entre o homem e o meio ambiente, surgindo a expressão "Desenvolvimento Sustentável". No Brasil, como reflexo deste evento surgem as primeiras preocupações em proteger o meio ambiente (Matos, 2001; Barros et al., 2008) como por exemplo, a criação da lei de Política Nacional de Meio Ambiente (PNMA), n ${ }^{\circ}$ 6.938/81, alterada pela Lei $\mathrm{n}^{\mathrm{o}}$ 10.165, em 27 de dezembro 2000. Essa lei foi de extrema importância para a legislação ambiental, resultando na criação do Sistema Nacional de Meio Ambiente (SISNAMA) e do Conselho Nacional de Meio Ambiente (CONAMA), (Resoluções CONAMA, 2003; 2006; 2009; 2013). A Resolução CONAMA n 335/2003, alterada pela Resolução $\mathrm{n}^{\mathrm{o}} 368 / 2006$, normatiza os procedimentos de licenciamento ambiental de cemitérios no país, com o propósito de minimizar os riscos ambientais que possam impactar o ambiente (CONAMA, 2003; 2006), porém, apesar de vigente não vem sendo devidamente cumprida.

A importância dessa normatização se dá em razão do sepultamento de corpos diretamente no solo, prática utilizada no Brasil desde o século XVII, aliado a precariedade de infraestrutura e a má administração dos cemitérios, contribuírem significativamente para a contaminação das áreas ocupadas por esse tipo de atividade potencialmente geradora de passivos ambientais e de saúde pública (Matos, 2001). Não obstante, a maioria dos cemitérios existentes terem sido implantados sem levar em consideração os aspectos geológicos, hidrogeológicos e geotécnicos da área em questão, pois não eram consideradas fontes poluidoras, fornecendo riscos potenciais de contaminação à saúde pública (Barros et al., 2008; Pacheco et al., 1991; WHO, 1998). Embora a decomposição de corpos presentes nesses locais seja um processo inerente ao meio natural, os mesmos podem conter substâncias tóxicas, como metais tóxicos, que demandam um tratamento especial, por não serem degradados biológica ou quimicamente (Hong et al., 2002). Esta contaminação dependendo de suas características físico-químicas podem lixiviar e contaminar as águas subterrâneas (Leli et al. 2012).

Os testes toxicológicos são uma importante ferramenta para fornecer informações sobre a biodisponibilidade desses poluentes, bem como auxiliar na correlação da contaminação e dos efeitos adversos sobre a biota local e do seu entorno (Lowe e Butt, 2007).

As Oligochaetas, popularmente conhecidas como minhocas são um importante grupo de organismos constituintes da macrofauna do solo e representam uma alternativa para investigar 
toxicidade, pois se encontram distribuídas na maior parte da biomassa dos solos tropicais. Exímias bioindicadoras de ecotoxicidade, fornecem referências sobre a biodisponibilidade dos poluentes e o grau de contaminação (Andréa, 2010; Shuster et al., 2002). Por meio de seu deslocamento e de ingestão do solo, as oligochaetas tem contato direto com os poluentes que estão adsorvidos nos colóides, na matéria orgânica e na solução aquosa, mas, podem ainda absorver os poluentes por meio de contato direto e passagem pela cutícula apresentando sintomas adversos ou morte por intoxicação (Andréa, 2010). Somando-se a isto, no Brasil, poucos estudos abordam a contaminação do solo de cemitério por poluentes metálicos e biodisponibilidade destes contaminantes, como relatam Kemerich et al. (2012). Também, não são encontrados relatos sobre a influência desta contaminação na biota do solo.

Este estudo foi realizado com o objetivo foi avaliar a toxicidade e a concentração de metais tóxicos do solo de dois cemitérios de Santa Maria, Rio Grande do Sul, sobre oligochaetas como bioindicadoras de contaminação.

\section{MATERIAL E MÉTODOS}

As amostras de solo foram coletadas em dois cemitérios no município de Santa Maria - Rio Grande do Sul. O primeiro localizado em zona urbana do município, denominado Cemitério Municipal de Santa Maria, em solo classificado como Argissolo Vermelho distrófico arênico (Unidade de Mapeamento São Pedro) (EMBRAPA, 2006), latitude $29^{\circ} 41^{\prime} 43.20^{\prime \prime} \mathrm{S}$ e longitude 5349'28.63" W, e o segundo cemitério localizado em área rural do município, denominado Cemitério Municipal São Marcos, em solo classificado como Chernossolo Argilúvico férrico típico (Unidade de Mapeamento Ciríaco) (EMBRAPA, 2006), latitude $29^{\circ} 40^{\prime} 14.40^{\prime \prime} \mathrm{S}$ e longitude 53 40'54.73" W. Removeu-se $20 \mathrm{~cm}^{3}$ de solo na área central de ambos os cemitérios, respeitando-se uma distância entre 5 a $10 \mathrm{~m}$ uma da outra.

Uma pá foi introduzida no solo descartando-se os primeiros $10 \mathrm{~cm}$ do perfil, utilizando-se apenas a camada de 10 a $20 \mathrm{~cm}$ do perfil nas análises químicas e toxicológicas, coletando-se um total de $0,008 \mathrm{~m}^{3}$ de solo por amostra. A escolha de coletar a uma profundidade de $20 \mathrm{~cm}$ decorreu devido ás circunstâncias atípicas do local, com jazigos muito próximos, impossibilitando outra forma de coleta. As amostras de solo foram misturadas, embaladas em sacos plásticos resistentes, lacrados, etiquetados e encaminhados ao Laboratório de Engenharia Ambiental - LABEA do Centro Universitário Franciscano, homogeneizado e disposto em bandejas para secagem ao ar.

$\mathrm{O}$ pH foi determinado em solução saturada 1:2,5, com água deionizada, permanecendo em repouso por 60 min (Tedesco et al., 1995), e o bioensaio de toxicidade aguda adotado segue o formato ensaio-limite (controle versus tratamento), completamente casualizado, com a utilização de 10 oligochaetas adultas, da espécie Eisenia andrei (Vermelha da Califórnia), pesando entre 300 e $400 \mathrm{mg}$ e clitelo desenvolvido. O bioensaio foi realizado em triplicata, composto por quatro tratamentos e dois níveis (SCU - Solo de Cemitério Urbano e SCR - Solo de Cemitério Rural): T0 - 100\% solo de mata +10 oligochaetas adultas; T1 - 50\% solo de cemitério $+50 \%$ solo de mata +10 oligochaetas adultas; $\mathrm{T} 2-75 \%$ solo de cemitério $+25 \%$ solo de mata +10 oligochaetas adultas e T3 $-100 \%$ solo de cemitério +10 oligochaetas adultas.

Adotaram-se como unidades experimentais, vasos de PVC escuro furado no fundo, cobertos com plástico do tipo Sombrite, mantidos em ambiente com luz solar difusa. A exposição dos organismos teste se deu simultaneamente tanto às amostras de solo controle e contaminado como a umidade e alimentação, que foram mantidas pela adição de $500 \mathrm{~mL}$ de água destilada em intervalos de 3 dias e $15 \mathrm{~g}$ de esterco bovino seco e pulverizado, em intervalos de 7 dias durante um período de exposição de 90 dias, conforme as normas ISO 17512-1 - Soil quality - Avoidance test for determining the quality of soils and effects of 
chemicals on behaviour - Part 1: Test with earthworms (Eisenia fetida and Eisenia andrei) (ISO, 2008).

Após 96 horas de exposição realizou-se a avaliação do número de indivíduos mortos para o cálculo da $\mathrm{CL}_{50}$ do solo para as oligochaetas. Após a contagem dos indivíduos mortos remontou-se as unidades experimentais, colocando nas mesmas condições ambientais do teste agudo, por aproximadamente 90 dias, para avaliar o efeito tóxico crônico (reprodução). A $\mathrm{CL}_{50}$, concentração letal que mata $50 \%$ dos indivíduos expostos foi obtida pela transformação logarítmica das concentrações em probitos do percentual de mortos, que converte a curva dose-resposta, sigmoide, em uma reta que pode, assim, ser analisada por regressão linear simples, realizada, neste trabalho, no programa BioEstat 5.0.

Depois de realizado o ensaio da biodisponibilidade de metais tóxicos no solo, as amostras de solo de ambos os cemitérios determinou-se a concentração de metais tóxicos no Laboratório de Absorção Atômica do Departamento de Engenharia Química da Escola de Engenharia de Lorena - Universidade de São Paulo (USP), por Espectrometria de Emissão Ótica com Plasma Acoplado Indutivamente (ICP-OES).

Nas determinações realizadas, utilizou-se o ICP-OES modelo Optima DV 4300 da Perkin Elmer, facilitando a observação do plasma no modo de configuração axial e radial, assegurando uma observação mais sensível para cada elemento. As condições de análise do ICP-OES estão descritas na Tabela 1.

Para a digestão das amostras de solo foram empregados os procedimentos de abertura de amostras de origem ambiental por digestão ácida conforme proposto por Bianchi e colaboradores (2012) e Salazar e colaboradores (2011b).

Tabela 1. Parâmetros instrumentais do ICP-OES para a análise qualiquantitativa de metais tóxicos nos tratamentos com solo de cemitério com ou sem adição de oligochaetas.

\begin{tabular}{|c|c|}
\hline Parâmetro da análise & Valor \\
\hline Vazão de Argônio & $10 \mathrm{~L} / \mathrm{min}$ \\
\hline Vazão do Nebulizador & $0,54 \mathrm{~L} / \mathrm{min}$ \\
\hline Vazão de o Gás Auxiliar & $0,2 \mathrm{~L} / \mathrm{min}$ \\
\hline Referência de Leitura & $15 \mathrm{~mm}$ \\
\hline Potência da Rádio Frequência & $1450 \mathrm{~W}$ \\
\hline Vazão da Bomba Peristáltica & $1,50 \mathrm{~mL} / \mathrm{min}$ \\
\hline Equação da Curva & $\begin{array}{l}\text { Curva forçada ao zero/Cálculo } \\
\text { de integração de área }\end{array}$ \\
\hline Tipo de Nebulizador & $\begin{array}{l}\text { Nebulizador de fluxo cruzado } \\
\text { acoplado à câmara do Scott }\end{array}$ \\
\hline Posição da Tocha & -3 \\
\hline Comprimento de onda (nm) & $\begin{array}{l}\text { Al }(396,153), \mathbf{C a}(317,933), \\
\mathbf{C d}(228,802), \mathbf{C r}(267,716), \\
\mathbf{C u}(327,398), \mathbf{F e}(238,204), \\
\mathbf{M g}(285,213), \mathbf{N i}(231,604), \\
\mathbf{P b}(220,356), \mathbf{Z n}(206,203)\end{array}$ \\
\hline
\end{tabular}

Os dados das análises químicas dos metais tóxicos foram testados pela Análise de Variância Simples, utilizando o software ESTATISTICA. 


\section{RESULTADOS E DISCUSSÃO}

Nas Tabelas 2 e 3 encontram-se discriminadas as transformações dos dados resultantes do bioensaio de toxicidade aguda e o valor da concentração letal média $\left(\mathrm{CL}_{50}\right)$ das diferentes concentrações de solo dos cemitérios (urbano e rural) testados neste experimento. Nas figuras 1 e 2 são apresentadas as curvas dose-resposta para ambos os cemitérios avaliados (urbano e rural).

Considerando os valores da $\mathrm{CL}_{50}$ dos solos dos cemitérios urbano e rural $\left(239,88 \mathrm{mg} \mathrm{kg}^{-1}\right.$ e $52,48 \mathrm{mg} \mathrm{kg}^{-1}$ ) respectivamente, pode-se observar que o solo do cemitério rural pode ser classificado como muito tóxico $\left(\mathrm{CL}_{50} \leq 100\right)$, muito próximo de extremamente tóxico $\left(\mathrm{CL}_{50} \leq 50\right)$, para as oligochaetas. A razão desta afirmação é que a quantidade de solo do cemitério rural (contaminado), necessária para matar 50\% dos organismos expostos, é inferior a quatro vezes a quantidade de solo do cemitério urbano no qual a $\mathrm{CL}_{50}$ foi $>100$, o que representa uma toxicidade moderada. Ribeiro et al. (2012) verificaram que minhocas da espécie Eisenia andrei, de mesma espécie das utilizadas neste estudo, quando expostas a solos e húmus contaminado com cobre, na concentração de $500 \mathrm{mg} \mathrm{kg}^{-1}$ tiveram $90 \%$ de letalidade.

Tabela 2. Valores percentuais de mortos transformados em Probit e $\mathrm{CL}_{50}$, do bioensaio de toxicidade aguda em Oligochaetas (minhoca) expostas a diferentes concentrações de solo do cemitério urbano.

\begin{tabular}{cccccccc}
\hline $\begin{array}{c}\text { Grupo } \\
\text { Teste }\end{array}$ & $\begin{array}{c}\text { (a) } \\
\mathrm{N}^{\mathbf{0}} \text { org. } \\
\text { (oligochaetas) }\end{array}$ & $\begin{array}{c}\text { (b) } \\
\text { Conc. Solo } \\
\text { cemitério }\left(\mathrm{g} \mathrm{kg}^{-1}\right)\end{array}$ & $\begin{array}{c}\text { (c) } \\
\text { Log. Conc. }\end{array}$ & $\begin{array}{c}\text { (d) } \\
\mathrm{N}^{\mathrm{o}} \text { mortos }\end{array}$ & $\begin{array}{c}\text { (e) } \\
\% \text { mortos }\end{array}$ & $\begin{array}{c}\text { (f) } \\
\text { Pobits }\end{array}$ & $\begin{array}{c}\text { (f) } \\
\mathrm{CL}_{50} \mathrm{mg} \mathrm{kg}^{-1}\end{array}$ \\
\hline T0 & 30 & 0 & 0 & 0 & 0 & 0 & \\
$\mathrm{~T} 1$ & 30 & 500 & 2,70 & 4 & 13,3 & 3.87 & 239,88 \\
$\mathrm{~T} 2$ & 30 & 750 & 2,90 & 7 & 23,3 & 4.26 & \\
$\mathrm{~T} 3$ & 30 & 1000 & 3,00 & 28 & 93,3 & 6.48 & \\
\hline
\end{tabular}

Nota: Número de organismos testados (a), concentração de solo contaminado (b), log. da concentração (c), número de organismos mortos (d), percentual de organismos mortos (e), probito do percentual de organismos mortos (f) e $\mathrm{CL}_{50}(\mathrm{~g})$.

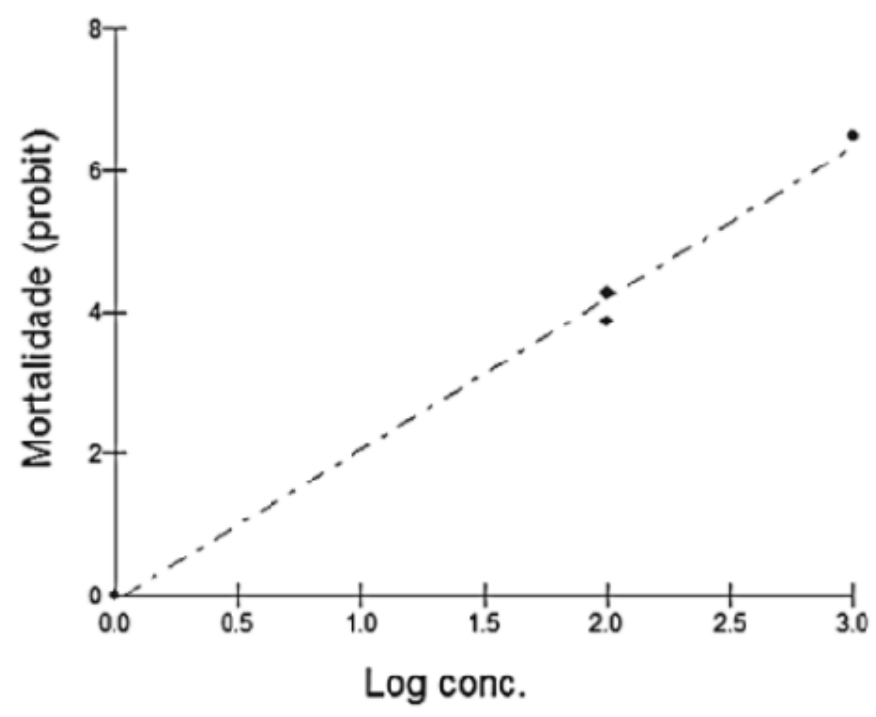

Figura 1. Relação dose-resposta do solo do cemitério urbano em oligochaetas com a transformação Probit 
Tabela 3. Valores percentuais de mortos transformados em Probit e CL50, do bioensaio de toxicidade aguda em Oligochaetas (minhoca) expostas a diferentes concentrações de solo do cemitério rural.

\begin{tabular}{|c|c|c|c|c|c|c|c|}
\hline $\begin{array}{l}\text { Grupo } \\
\text { Teste }\end{array}$ & $\begin{array}{c}\text { (a) } \\
\mathrm{N}^{\mathrm{o}} \text { org. } \\
\text { (oligochaetas) } \\
\end{array}$ & $\begin{array}{c}\text { (b) } \\
\text { Conc. Solo } \\
\text { cemitério (g.kg- }{ }^{1} \text { ) }\end{array}$ & $\begin{array}{c}\text { (c) } \\
\text { Log. Conc. }\end{array}$ & $\begin{array}{c}\text { (d) } \\
\mathrm{N}^{\mathrm{o}} \text { mortos }\end{array}$ & $\begin{array}{c}\text { (e) } \\
\% \text { mortos }\end{array}$ & $\begin{array}{c}(f) \\
\text { Probits }\end{array}$ & $\stackrel{\text { (g) }}{\text { CL }} \stackrel{\text { mg. }}{\text { mg.kg }}{ }^{-1}$ \\
\hline T0 & 30 & 0 & 0 & 0 & 0 & 0 & \multirow{4}{*}{52,48} \\
\hline $\mathrm{T} 1$ & 30 & 500 & 2,70 & 23 & 76,7 & 5.71 & \\
\hline $\mathrm{T} 2$ & 30 & 750 & 2,90 & 28 & 93,3 & 6.48 & \\
\hline T3 & 30 & 1000 & 3,00 & 30 & 100 & 8.09 & \\
\hline
\end{tabular}

Nota: Número de organismos testados (a), concentração de solo contaminado (b), log. da concentração (c), número de organismos mortos (d), percentual de organismos mortos (e), probito do percentual de organismos mortos (f) e $\mathrm{CL}_{50}(\mathrm{~g})$

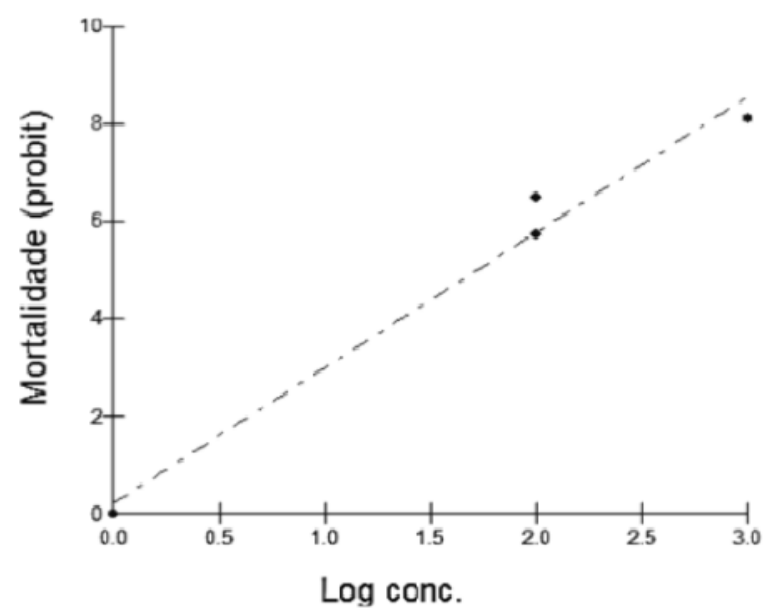

Figura 2. Relação dose-resposta do solo do cemitério urbano em oligochaeta com a transformação Probit.

A Figura 3 representa os percentuais de morte observados nos tratamentos T1, T2 e T3 nos quais se evidencia que quanto maior o percentual de solo contaminado adicionado maior é o número de indivíduos expostos mortos. Observa-se também que esses percentuais são superiores nos tratamentos que envolveram solo do cemitério rural. Considerando que foram adotados os mesmos tratamentos e procedimentos para ambos os cemitérios testados, pode-se inferir que o solo do cemitério rural, quer por suas características físico-químicas ou condições de construção, apresenta maior potencial tóxico que o solo do cemitério urbano.

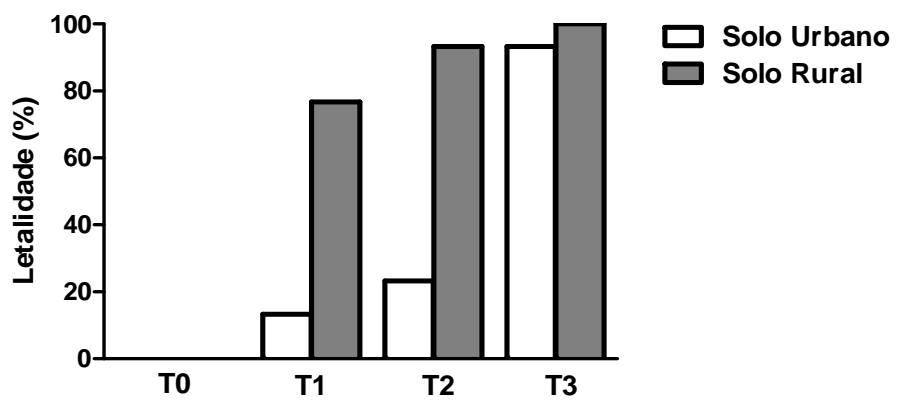

Figura 3. Letalidade nos diferentes tratamentos. T0 $100 \%$ solo de mata; $\mathrm{T} 1-50 \%$ solo contaminado $+50 \%$ solo de mata; $\mathrm{T} 2-75 \%$ solo contaminado $+25 \%$ solo de mata e T3 - 100\% solo contaminado. 
Os teores totais de Cádmio $(\mathrm{Cd})$, Cobre $(\mathrm{Cu})$, Cromo $(\mathrm{Cr})$, Chumbo $(\mathrm{Pb})$, Níquel $(\mathrm{Ni})$ e Zinco ( $\mathrm{Zn}$ ), detectados neste estudo, equiparados aos valores de referência propostos pela Resolução CONAMA 420, de dezembro de 2009 alterada pela Resolução CONAMA 460, de dezembro de 2013 (Tabela 4), evidenciam que apenas os metais $\mathrm{Cr}$ e $\mathrm{Ni}$ (em ambos os solos na concentração $100 \%$ ) estão acima dos valores de prevenção (VP).

Tabela 4. Concentração de metais tóxicos e valores de referência para o solo de mata e solo dos cemitérios urbano e rural.

\begin{tabular}{|c|c|c|c|c|}
\hline \multirow[b]{2}{*}{ Parâmetros } & \multicolumn{4}{|c|}{ Valores $\mathrm{mg} \mathrm{kg}^{-1}$} \\
\hline & $\begin{array}{c}\text { Prevenção } \\
\text { (CONAMA) }\end{array}$ & $\begin{array}{l}\text { Solo controle } \\
\text { (Mata) }\end{array}$ & $\begin{array}{l}\text { Solo urbano } \\
(100 \%)\end{array}$ & $\begin{array}{c}\text { Solo rural } \\
(100 \%)\end{array}$ \\
\hline $\mathrm{Cd}$ & 1,3 & 0,094 & $0,134^{\mathrm{ns}}$ & $0,106^{\mathrm{ns}}$ \\
\hline $\mathrm{Cr}$ & 75 & 9,34 & $163,68 * *$ & $172,56^{* *}$ \\
\hline $\mathrm{Cu}$ & 60 & 7,43 & $13,19^{\text {ns }}$ & $19,16^{\mathrm{ns}}$ \\
\hline $\mathrm{Ni}$ & 30 & 3,03 & $61,69^{* *}$ & $63,81 * *$ \\
\hline $\mathrm{Pb}$ & 72 & 7,43 & $16,20^{\mathrm{ns}}$ & $22,47^{\mathrm{ns}}$ \\
\hline $\mathrm{Zn}$ & 300 & 17,79 & $95,08^{\text {ns }}$ & $53,02^{\text {ns }}$ \\
\hline
\end{tabular}

Ns $=$ não significativo; $*$ significativo a 0,$05 ; * *$ significativo a 0.10 . Análise de variância (ANOVA One-Way).

As concentrações totais dos demais metais analisados (Al, $\mathrm{Ca}, \mathrm{Fe}, \mathrm{Mg}$ ) ficaram abaixo dos Valores de Prevenção (VP- concentração que pode afetar negativamente a qualidade do solo), estabelecidos conforme CONAMA n $\mathrm{n}^{\mathrm{o}}$ 420/2009. Desta forma, $\mathrm{Cu}, \mathrm{Pb}$ e $\mathrm{Zn}$, estão enquadrados no Valor de Referência de Qualidade (VRQ), sendo atóxicos nas concentrações detectadas para ambos os solos. Cromo (Cr) e Níquel (Ni) não existem no organismo, porém são necessários para a manutenção do seu funcionamento e, portanto, requeridos em concentrações muito baixas, acima das quais se tornam extremamente tóxicos (Siqueira et al., 1994, Salazar et al, 2011a), provavelmente tenham sido os responsáveis pela mortalidade das oligochaetas expostas. Outra possível explicação para a toxicidade do $\mathrm{Cr}$ ter sido superior pode ser devido ao $\mathrm{Cr}^{+}$, apesar de ligar-se fortemente a sítios negativos de argila e matéria orgânica (Mengel e Kirkby, 1982), em solos mais arenosos como o solo do cemitério rural, tem maior mobilidade e, portanto, maior biodisponibilidade.

$\mathrm{Na}$ maioria dos solos a concentração não ultrapassa $60 \mathrm{mg} \mathrm{kg}^{-1} \mathrm{e}$, portanto, segundo WHO (1988) quase todo cromo hexavalente, forma mais tóxica tanto para plantas como para animais é resultante das atividades humanas. Por essa razão, no caso dos solos de cemitério, esses metais muito provavelmente são oriundos, principalmente, dos banhos de cromação dos adornos dos caixões e tintas e vernizes preservativos das madeiras usados na fabricação dos caixões e das urnas de metal. Relatos sobre a toxicidade do cromo em animais terrestes são escassos, porém, WHO (1988) cita também que a toxicidade para a maioria dos microorganismos ocorre na faixa de $0,05 \mathrm{mg} \mathrm{kg}^{-1}$.

A Figura 4 compara as concentrações de $\mathrm{Cd}, \mathrm{Cr}, \mathrm{Cu}, \mathrm{Ni}, \mathrm{Pb}$ e $\mathrm{Zn}$ detectadas neste experimento com os valores CONAMA 420\2009. Nesta figura, pode-se observar que tanto Cromo como Niquel foram encontrados acima dos valores de prevenção CONAMA $420 \backslash 2009$. 


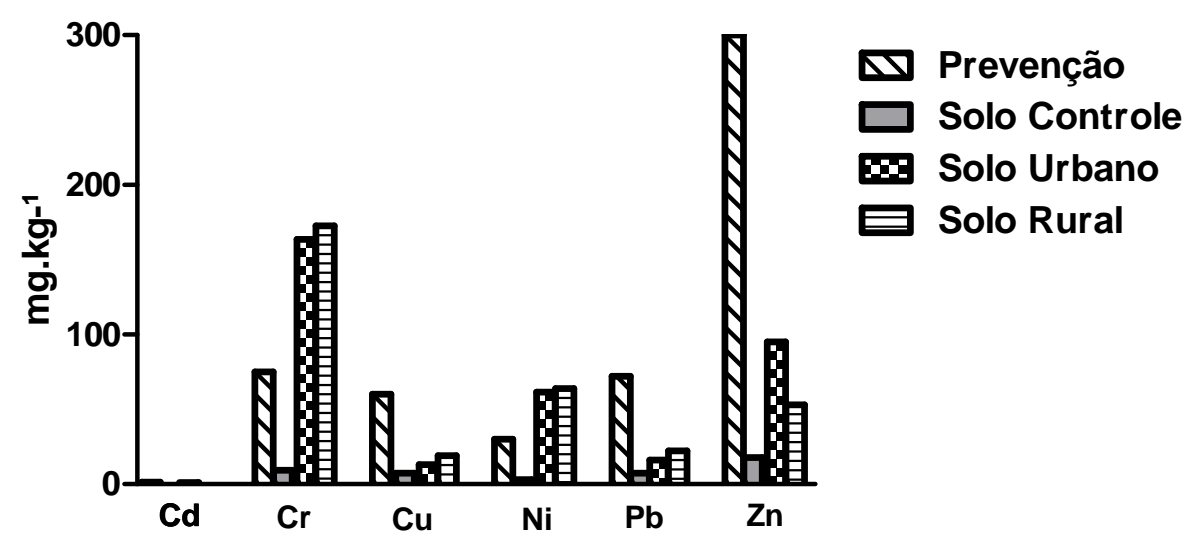

Figura 4. Concentração dos elementos em comparação com valores de referência (prevenção) CONAMA 420/2009.

Analisando os valores de cromo ( $\mathrm{Cr}$ ) detectados nos dois tipos de solos (urbano e rural), observam-se valores acentuados na concentração $100 \%$, com a ausência das oligochaetas, em ambos os casos (Figura 5 a e b).

Ao contrário, nos tratamentos que receberam oligochaetas, se observou comportamento diferenciado, no solo do cemitério urbano $(100 \%+$ oligochaetas $)$ houve decréscimo significativo na concentração do metal, porém, no solo do cemitério rural, na mesma condição o decréscimo foi superior.

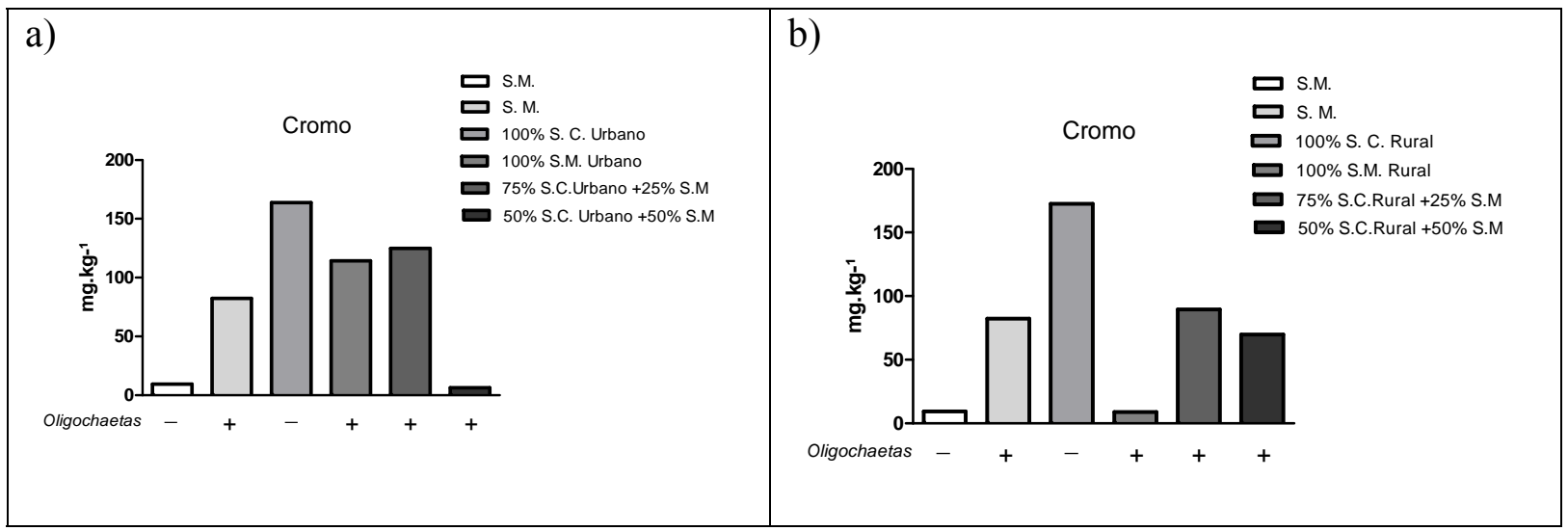

Figura 5. Comportamento do Cromo (Cr) em: a) solo de cemitério urbano com e sem oligochaetas, nas concentrações $0 \%, 100 \%, 75 \%$ e $50 \%$ e, b) solo de cemitério rural.

Segundo Macedo e Morril (2008), o Cromo, por participar dos processos metabólicos da glicose, tem sido considerado essencial para homens e animais e, por essa razão, acredita-se que a absorção do metal pelas oligochaetas foi superior em relação aos outros metais. Entretanto, quando presentes em amostras ambientais de água e solos acidificados esse elemento apresenta estado de oxidação hexavalente $\mathrm{Cr}(\mathrm{VI})$, podendo ser extremamente tóxico à biota local (Salazar et al., 2011b; Bianchi et al., 2012). Há que se considerar, ainda, a presença do metal no esterco bovino adicionado ao solo conforme propõem Gonçalves et al. (2007).

O comportamento do Níquel, ilustrado na Figura 6 (a e b), mostrou-se muito semelhante ao observado para o Cromo, em ambos os solos (urbano e rural). Contudo, ao compararmos o comportamento do metal no solo urbano com o comportamento apresentado no solo rural, o mesmo revela comportamento contrastante na concentração $100 \%$ solo de cemitério com presença de oligochaetas, no qual a concentração do metal reduziu. Além de apresentar, 
também, uma queda drástica no tratamento que continha solo de cemitério e solo de mata na mesma proporção. Nesta condição observa-se também que o Níquel teve um comportamento, principalmente no solo do cemitério rural, muito semelhante ao observado para o cromo.

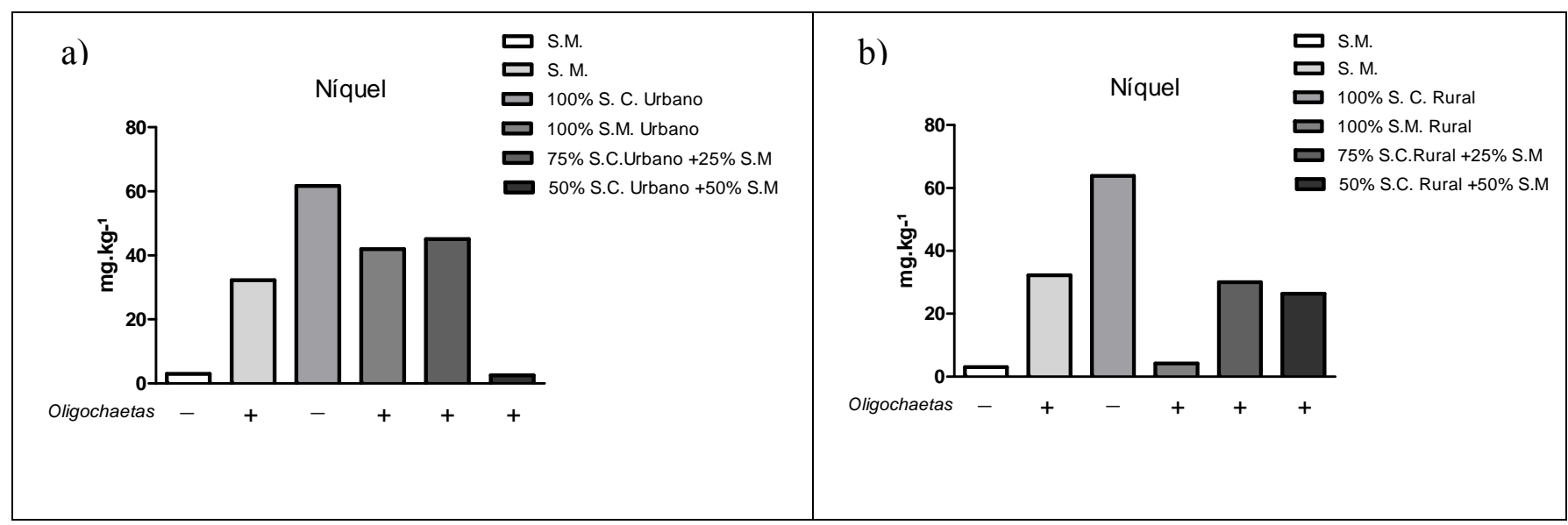

Figura 6. Comportamento dos metais tóxicos Níquel (Ni) em: a) solo de cemitério urbano; b) solo de cemitério rural e em solo de cemitério urbano.

Uma possível explicação para o comportamento do níquel seria de que como esse metal tem a propriedade de formar complexos na forma de quelatos com os compostos orgânicos do solo (Gonçalves et al., 2007; Salazar et al., 2011a), a matéria orgânica (esterco bovino) adicionada semanalmente às unidades experimentais tenha favorecido essa absorção do metal às partícula de solo e, consequentemente, a ingestão do metal junto com a matéria orgânica, reduzindo seu teor nos tratamentos contendo oligochaetas.

\section{CONCLUSÃO}

A presença de contaminantes como metais tóxicos nas concentrações detectadas neste trabalho comprometem a vida de um dos mais importantes grupos da macrofauna edáfica, as oligochaetas, indicadoras de toxicidade. Dentre os metais tóxicos que podem ser liberados no solo de cemitérios implementados em condições inadequadas, Cromo e Níquel, quando em concentrações elevadas são os que têm maior potencial para afetar a vida das oligochaetas. $\mathrm{O}$ cemitério é um empreendimento potencialmente poluidor, quando construído em local sem estudo prévio, principalmente em relação ao tipo de solo. Por fim, este aumento de substâncias tóxicas nos recursos naturais, deve ser analisado pelos órgãos competentes, pois o risco de tornar os recursos naturais desses locais, como o solo e os corpos hídricos subterrâneos inutilizáveis, é iminente.

\section{REFERÊNCIAS}

ANDRÉA, M. M. de. O uso de minhocas como bioindicadores de contaminação de solos. Acta Zoológica Mexicana, v. Especial 2, p. 95-107, 2010.

BARROS, Y. J.; MELO, V. F.; ZANELLO, S.; ROMANO, E. N. L.; LUCIANO, P. R.. Teores de metais pesados e caracterização mineralógica de solos do Cemitério Municipal de Santa Cândida, Curitiba (PR). Revista Brasileira de Ciência do Solo, v. 32, p. 1763-1773, 2008. http://dx.doi.org/10.1590/S0100-06832008000400041 
BIANCHI, S. R.; AMAIS, R. S.; PEREIRA, C. D.; SALAZAR, R. F. S.; NÓBREGA, J. A.; NOGUEIRA, A. R. A. Evaluation of a Collision-Reaction Interface (CRI) for Carbon Effect Correction on Chromium Determination in Environmental Samples by ICP-MS. Analytical Letters, v. 45, n. 18, p. 2845-2855, 2012. http://dx.doi.org/10.1080/00032719.2012.702176

CONSELHO NACIONAL DO MEIO AMBIENTE. Resolução 335, de 3 de abril de 2003. Dispõe sobre o licenciamento ambiental de cemitérios. Diário Oficial [da] União, Brasília, n. 101, 28 maio 2003, Seção 1, p. 98-99.

CONSELHO NACIONAL DO MEIO AMBIENTE. Resolução 368, de 28 de março de 2006. Altera dispositivos da Resolução 335, de 3 de abril de 2006, que dispõe sobre o licenciamento ambiental de cemitérios. Diário Oficial [da] União, Brasília, n. 61, 29 mar. 2006, Seção 1, p. 149-150.

CONSELHO NACIONAL DO MEIO AMBIENTE. Resolução 420, de 28 de dezembro de 2009. Dispõe sobre critérios e valores orientadores de qualidade do solo quanto à presença de substâncias químicas e estabelece diretrizes para o gerenciamento ambiental de áreas contaminadas por essas substâncias em decorrência de atividades antrópicas. Diário Oficial [da] União, Brasília, n. 249, 30 dez. 2009, Seção 1, p. 81-84.

CONSELHO NACIONAL DO MEIO AMBIENTE. Resolução 460, de 30 de dezembro de 2013. Altera a Resolução CONAMA 420, de 28 de dezembro de 2009, que dispõe sobre critérios e valores orientadores de qualidade do solo quanto à presença de substâncias químicas e dá outras providências. Diário Oficial [da] União, Brasília, n. 253, 31 dez. 2013, Seção 1, p. 153.

EMPRESA BRASILEIRA DE PESQUISA AGROPECUÁRIA - EMBRAPA. Sistema brasileiro de classificação de solo. 2. ed. Rio de Janeiro, 2006. 306 p.

GONÇALVES JR, A. C.; POZZA, P. C.; NACKE, H.; LAZZERI, D. B.; SELZLEIN, C.; CASTILHA, L. D. Homogeneização e níveis de metais em dejetos provenientes da bovinocultura de leite. Acta Scientiarum Technology, v. 29, p. 213-217, 2007. http://dx.doi.org/10.4025/actascitechnol.v29i2.712

HONG, K. J.; TOKUNAGA, S.; KAJIUCHI, T. Evaluation of remediation process with plant-derived biosurfactant for recovery of heavy metals from contaminated soils. Chemosphere, v. 49, p. 379-387, 2002. http://dx.doi.org/10.1016/S00456535(02)00321-1

INTERNATIONAL ORGANIZATION FOR STANDARDIZATION. ISO 17512-1: Soil quality - Avoidance test for testing the quality of soils and the toxicity of chemicals on behaviour - Part 1: Test with earthworms (Eisenia fetida and Eisenia andrei). Geneva, 2008.

KEMERICH, P. D. da C.; BORBA, F. de; SILVA, R. F. da; BARROS, G.; GERHARDT, A. E.; FLORES, C. E. B. Valores anômalos de metais pesados em solo de cemitério. Revista Ambiente \& Água, v. 7, n. 1, 2012. http://dx.doi.org/10.4136/ambi-agua.838

LELI, I. T.; ZAPAROLI, F. C. M.; SANTOS, V. C.; OLIVEIRA, M.; VIEIRA, F. A. G. Estudos ambientais para cemitérios: Indicadores, áreas de influência e impactos ambientais. Boletim de Geografia, v. 30, p. 45-54, 2012. http://dx.doi.org/10.4025/bolgeogr.v30i1.16348 
LOWE, C. N.; BUTT, K. R. Earthworm culture, maintenance and species selection in chronic ecotoxicological studies: a critical review. European Journal of Soil Biology, v. 43, p. 281-288, 2007. http://dx.doi.org/10.1016/j.ejsobi.2007.08.028

MACÊDO, L. S.; MORRIL, W. B. B. Origem e comportamento dos metais fitotóxicos: revisão da literatura. Tecnologia \& Ciência Agropecuária, v. 2, p. 2-38, 2008.

MATOS, B. A. Avaliação da ocorrência e do transporte de micronutrientes no aqüífero freático do cemitério de Vila Nova Cachoeirinha. 2001. 113 f. Tese (Doutorado em Recursos Minerais e Hidrogeologia) - Universidade de São Paulo, São Paulo, 2001.

MENGEL, K.; KIRKBY, E. A. Principles of plant nutrition. Worblanfe-Bern: International Potash Institute, 1982. $655 \mathrm{p}$.

PACHECO, A.; MENDES, J. M. B.; MARTINS, T.; HASSUDA, S.; KIMMELMANN, A. A. Cemeteries: a potential risk to groundwater. Water Science and Technology, v. 24, p. 97-104. 1991.

RIBEIRO, R.; HOEHNE, L.; MANICA, W.; CARLESSO, E. ETHUR, M.; STÜLP, S. A Absorção de cobre por minhocas da espécie Eisenia andrei em solos e húmus contaminados. Revista Destaques Acadêmicos, v. 4, n. 4, 2012.

SALAZAR, R. F. S.; ALCÂNTARA, M. A. K.; IZÁRIO FILHO, H. J. Evaluation of sample preparation methods and optimization of nickel determination in vegetable tissues. Revista Brasileira de Ciência do Solo, v. 35, n. 1, p. 241-248, 2011 la. http://dx.doi.org/10.1590/S0100-06832011000100022

SALAZAR, R. F. S.; GUERRA, M. B. B.; PEREIRA-FILHO, E. R.; NÓBREGA, J. A. Performance evaluation of collision-reaction internal stadardization in quadrupole ICPMS measurements. Talanta, v. 86, n. 1, p. 241-247, $2011 \mathrm{~b}$. http://dx.doi.org/10.1016/j.talanta.2011.09.009

SHUSTER, W. D.; SUBLER. S.; MCCOY. E. L. The influence of earthworm community structure on the distribution and movement of solutes in a chisel-tilled soil. Applied Soil Ecology, v. 21, p. 159-167, 2002. http://dx.doi.org/10.1016/S0929-1393(02)00063$\mathrm{X}$

SIQUEIRA, J. O.; MOREIRA, F. M. S.; GRISI, B. M.; HUNGRIA, M.; ARAÚJO, R. S. Microorganismo e processos biológicos do solo: perspectiva ambiental. Brasília, DF: EMBRAPA/CNPAF/CNPS, 1994. 142p. (Documentos, 45).

TEDESCO, M. J.; GIANELLO, C.; BISSANI, C. A. et al. Análise de solo, plantas e outros materiais. 2. ed. Porto Alegre: Departamento de Solos, UFRGS, 1995.174 p. (Boletim Técnico, 5).

WORLD HEALTH ORGANIZATION - WHO. Chromium. Geneva: Environmental Health Criteria, 1988. 61p.

WORLD HEALTH ORGANIZATION - WHO. The impact of cemeteries on the environment and public health: an Introductory briefing. Copenhagen: Regional Office for Europe, 1998. $11 \mathrm{p}$. 